\title{
Associação entre El Niño Oscilação Sul e a produtividade do milho no Estado do Rio Grande do Sul
}

\author{
Moacir Antonio Berlato(1) Homero Farenzena(1) e Denise Cybis Fontana $^{(1)}$
}

(1)Universidade Federal do Rio Grande do Sul, Dep. de Plantas Forrageiras e Agrometeorologia, Av. Bento Gonçalves 7712, Caixa Postal, 15.100, CEP 91501-970 Porto Alegre, RS. E-mail: moacir.berlato@ufrgs.br, homero@net.crea-rs.org.br, dfontana@ufrgs.br

\begin{abstract}
Resumo - A alta variabilidade interanual da produtividade de milho, no Rio Grande do Sul, é determinada, principalmente, pela variabilidade da precipitação pluvial, e esta, em grande parte está associada ao fenômeno El Niño Oscilação Sul (ENOS). A disponibilidade, hoje, de previsões sazonais do ENOS faz vislumbrar a possibilidade de uso dessas informações para minimizar prejuízos e maximizar a produtividade. Há necessidade, porém, de se avaliar a vulnerabilidade da produtividade do milho a esse fenômeno. O objetivo deste trabalho foi quantificar a associação entre a produtividade de milho e a variabilidade da precipitação pluvial, causada pelo ENOS. Para a análise, foram tomadas séries históricas de produtividade, de precipitação pluvial mensal, de ocorrência das fases do ENOS (El Niño e La Niña), de Temperatura da Superfície do Mar (TSM) no Pacífico equatorial, e do Índice de Oscilação Sul (IOS). Há forte tendência do El Niño em favorecer a cultura do milho, o que dá oportunidade à alta produtividade, ao passo que em anos de ocorrência de La Niña há alta freqüência de baixa produtividade. A precipitação pluvial mais associada à produtividade do milho é a integrada de outubro a março. Essas informações são úteis para decisões quanto a alternativas de manejo da cultura, frente a uma previsão de El Niño ou La Niña.
\end{abstract}

Termos para indexação: Zea mays, La Niña, precipitação pluvial.

\section{Association between El Niño Southern Oscillation and corn yield in Rio Grande do Sul State}

\begin{abstract}
The high interannual variability of corn yield in Rio Grande do Sul State is determined mostly by the variability of rainfall, which is mainly associated to El Niño Southern Oscillation (ENSO). Current availability of seasonal ENSO forecasts shows the possibility of using this information to minimize losses and maximize yield. However, it is necessary to assess the vulnerability of corn yield to this phenomenon. The objective of this work was to quantify the association between corn yield and rainfall variability due to ENSO. In order to perform the analysis, historical series of yields, monthly rainfalls, ENSO (El Niño and La Niña) phases, Sea Surface Temperature (SST) in equatorial Pacific, and the Southern Oscillation Index (SOI) were used. Results show that there is a strong trend for El Niño to favor corn crops, providing opportunities for high yields, while in years when La Niña occurs there is a high frequency of low yields. The rainfall most associated with corn yields is the integrated one from October to March. This information is useful for decision making as to crop management alternatives when there is a forecast of El Niño or La Niña.
\end{abstract}

Index terms: Zea mays, La Niña, rainfall.

\section{Introdução}

O milho é, atualmente, a segunda maior cultura agrícola do Estado do Rio Grande do Sul, em termos de área cultivada, e a terceira em produção de grãos. $\mathrm{Na}$ safra 2000/2001, a área colhida foi de 1,668 milhão de hectares, com uma produção de 6,090 milhões de toneladas e produtividade média de $3.650 \mathrm{~kg} \mathrm{ha}^{-1}$ (Ribeiro, 2003). No mesmo ano, sua participação em relação ao total de grãos produzidos no Estado foi de
$24 \%$ da área cultivada e $32 \%$ da produção total. O Estado é, também, grande produtor nacional de milho; na safra 2000/2001 colheu 14\% da área e produziu $15 \%$ da produção nacional. O milho desempenha papel relevante na economia agrícola do Estado, pois a cadeia alimentícia desse cereal inclui a suinocultura, a avicultura e o gado leiteiro (Mundstock, 2004).

Tendo em vista que, praticamente, a totalidade do milho produzido no Estado é de lavoura de sequeiro, a produtividade e a produção apresentam grande variabilidade 
interanual, determinada em grande parte pela variabilidade da precipitação pluvial.

Vários autores (Matzenauer \& Fontana, 1987; Matzenauer et al., 1995) têm mostrado a relação entre produtividade do milho e condições hídricas, especialmente no período mais crítico dessa cultura em relação à água (pendoamento-espigamento). Em geral, esses estudos foram feitos com experimentos no campo e, portanto, com vários fatores como fertilidade do solo, cultivar, densidade populacional, controle fitossanitário, e outros, mantidos como constantes. Poucos trabalhos, com dados para todo o Estado, foram realizados com análises de séries históricas de produtividade de lavoura.

O Rio Grande do Sul, situado no extremo meridional do Brasil, pertence à chamada Região Sudeste da América do Sul (Sul do Brasil, Nordeste da Argentina, Uruguai e Sul do Paraguai), que apresenta forte sinal do fenômeno El Niño Oscilação Sul (ENOS), especialmente em relação à precipitação pluvial (Ropelewski \& Halpert, 1987; Rao \& Hada, 1990; Studzinski \& Diaz, 1994; Diaz et al., 1998; Grimm et al., 1998; Montecinos et al., 2000). O ENOS é um fenômeno de interação oceano-atmosfera, que ocorre no Oceano Pacífico tropical, e é considerado como a principal causa da variabilidade climática em diversas regiões do Globo. Apresenta duas fases extremas: uma fase quente denominada El Niño e uma fase fria denominada La Niña (Berlato \& Fontana, 2003).

No caso do Rio Grande do Sul, o El Niño produz anomalias positivas de precipitação pluvial e La Niña anomalias negativas, especialmente na primavera-início de verão do ano de início do fenômeno (Fontana \& Berlato, 1996; Puchalski, 2000).

Como já comprovado para a soja (Berlato \& Fontana, 1997, 2003), trigo (Cunha et al., 1999) e arroz (Carmona \& Berlato, 2002), para o milho também existem algumas evidências da relação entre variabilidade da produtividade e o fenômeno ENOS, no Rio Grande do Sul (Fontana \& Berlato, 1996), em duas localidades situadas na região significativa de produção de milho do Estado: Cruz Alta e Passo Fundo.

Graças aos avanços recentes do conhecimento da interação oceano-atmosfera, da modelagem e dos computadores, atualmente é possível prever as duas fases do ENOS (El Niño e La Niña), com alguma antecedência. Segundo Oliveira (1999), um marco histórico da previsão do fenômeno foi a previsão do El Niño de 1986/ 1987 pelo Lamonth-Doherth Earth Observatory da Columbia University, Estados Unidos da América.
A partir de 1990, os modelos foram aperfeiçoados e, atualmente, já se dispõe dessas previsões em caráter operacional. Essas previsões, embora ainda de média confiabilidade na Região Sul do Brasil, podem auxiliar no planejamento da agricultura, especialmente no que se refere ao calendário agrícola e ao manejo do solo e da água, com o fim de minimizar os impactos negativos da variabilidade climática e, também, para tirar proveito de situações climáticas favoráveis. No caso do milho, na região pampeana da Argentina, que apresenta o mesmo sinal do ENOS do Sul do Brasil, modelos de simulação possibilitaram retornos econômicos para os produtores rurais, com o uso de alternativas de datas de semeadura, aplicação de nitrogênio, densidade de plantas e híbridos em relação às fases do ENOS (Podestá et al., 2002). Entretanto, para se tirar maior proveito de previsões climáticas, como as baseadas no ENOS, é necessário avançar na quantificação da vulnerabilidade da produção agrícola à variabilidade climática, como a provocada pelo ENOS.

O objetivo deste trabalho foi quantificar a associação entre a produtividade do milho e a variabilidade da precipitação pluvial causada pelo ENOS.

\section{Material e Métodos}

Foi utilizada uma série histórica de dados de produtividade média de milho, no Estado do Rio Grande do Sul, no período compreendido entre os anos agrícolas de 1919/1920 e 2002/2003, obtida junto ao IBGE e à Emater-RS.

Os dados de precipitação pluvial mensal, do mesmo período, nas oito estações meteorológicas (Cruz Alta, Irai, Júlio de Castilhos, Passo Fundo, Santa Maria, Santa Rosa, São Luiz Gonzaga e Veranópolis) situadas na região significativa de produção do milho, foram obtidos do Oitavo Distrito de Meteorologia, do Instituto Nacional de Meteorologia ( $8^{\circ}$ Disme/ Inmet), e da Fundação Estadual de Pesquisa Agropecuária (Fepagro-RS) (Figura 1).

Os eventos de El Niño e La Niña, no período analisado, foram obtidos de Podestá et al. (1999), que estudaram a relação entre ENOS e a produtividade de várias culturas (inclusive o milho), no Centro-Leste da Argentina (Região do Pampa Argentino). A definição usada por Podestá et al. (1999), na caracterização das fases do ENOS, foi a adotada pela Agência Japonesa de Meteorologia (AJM) que, segundo Trenberth (1997), é 
objetiva e identifica bem os anos de El Niño e La Niña. O critério da AJM consiste na seleção de períodos, cuja média móvel de cinco meses da anomalia da temperatura da superfície do mar (TSM) da região equatorial do Oceano Pacífico (aproximadamente a região do chamado Niño 3) seja $\geq 0,5^{\circ} \mathrm{C}$ (E1 Niño) ou $\leq-0,5^{\circ} \mathrm{C}$ (La Niña) por, no mínimo, seis meses consecutivos.

À série apresentada por Podestá et al. (1999), que vai até 1991/1992, foram acrescentados os eventos do El Niño de 1992/1993, 1993/1994, 1994/1995, 1997/1998 e 2002/2003, e os eventos do La Niña de 1995/1996, 1998/1999 e 1999/2000. O evento de 1993/1994 foi caracterizado como El Niño (moderado a fraco) só até dezembro de 1993, mas para o milho é importante, por abranger parte significativa do calendário agrícola dessa cultura no Estado e, por isso, foi incluído (Figura 2). O calendário agrícola médio, da cultura do milho, no Rio Grande do Sul, foi extraído dos dados da Emater-RS, período 1993/1997.

O número de eventos, em cada fase do ENOS, segundo o método acima descrito, no período 1922/2003, é referente ao período de julho do ano de início do fenômeno, a junho do ano seguinte (E1 Niño: 1925-1926, 1929-1930, 1930-1931, 1940-1941, 1951-1952, 1957-

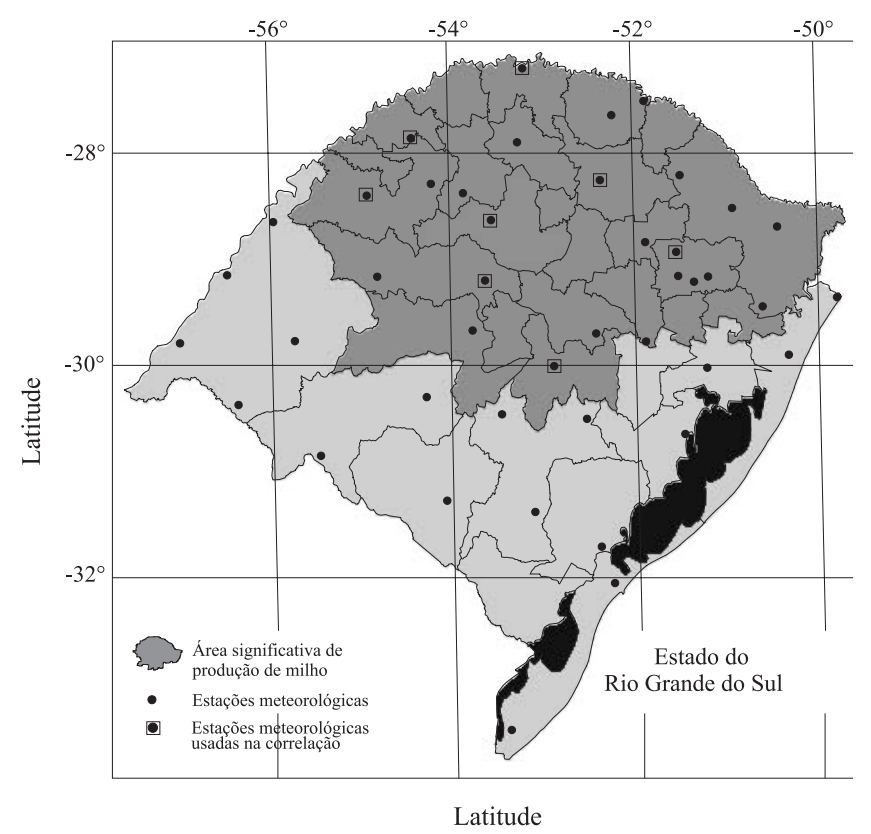

Figura 1. Região de produção significativa da cultura do milho, no Estado do Rio Grande do Sul, cerca de $80 \%$ da produção total. Fonte: Berlato \& Fontana (2003).
1958, 1963-1964, 1965-1966, 1969-1970, 1972-1973, 1976-1977, 1982-1983, 1986-1987, 1987-1988, 19911992, 1992-1993, 1993-1994, 1994-1995, 1997-1998, 2002-2003; La Niña: 1922-1923, 1924-1925, 19381939, 1942-1943, 1944-1945, 1949-1950, 1954-1955, 1955-1956, 1956-1957, 1964-1965, 1967-1968, 19701971, 1971-1972, 1973-1974, 1974-1975, 1975-1976, 1988-1989, 1995-1996, 1998-1999, 1999-2000) (Podestá et al., 1999, e dados acrescentados a partir de 1992-1993). As anomalias de TSM das regiões dos Niños e o Índice de Oscilação Sul (IOS) foram obtidos de Oliveira (1999).

Os cultivos agrícolas apresentam, em geral, uma tendência de aumento da produtividade através dos anos, por causa da melhoria da tecnologia de produção, como, por exemplo, material genético mais adaptado e melhores técnicas de manejo.

Para correlacionar a produtividade com variáveis meteorológicas, há necessidade de se remover a chamada tendência tecnológica. Uma técnica simples de avaliação da tendência tecnológica é a média móvel. No presente trabalho foi usada essa técnica e, com base na série histórica de 84 anos de produtividade do milho $\left(\mathrm{kg} \mathrm{ha}^{-1}\right)$ no Estado, foram feitas as médias móveis de diversos períodos; por inspeção gráfica, foi escolhida a média móvel de nove anos, que suavizou suficientemente a curva e filtrou a flutuação de alta freqüência, tendo permanecido a tendência de baixa freqüência ou de longo prazo. Os valores da tendência, nas duas pontas da série histórica, foram estimados por extrapolação. Foram obtidos os desvios ou resíduos absolutos de produtividade $\left(\mathrm{kg} \mathrm{ha}^{-1}\right)$, subtraindo-se o valor estimado de baixa freqüência (média móvel) do valor observado em cada ano.

A série histórica dos desvios, ordenada de maior a menor, foi dividida em três partes (tercis), obtendo-se o tercil superior, o tercil médio e o tercil inferior de produtividade. Os tercis de produtividade foram cotejados com as fases do ENOS (El Niño, La Niña e Neutro), mediante a técnica da Tabela de Contingência (Wilks, 1995).

A associação entre desvios de produtividade e precipitação pluvial foi estimada pela análise de correlação e regressão (Wilks, 1995).

Os desvios de produtividade, do período 1970/1971 a 2002/2003, foram relacionados, também, com a anomalia da Temperatura da Superfície do Mar (TSM), do Pacífico equatorial, e com o Índice de Oscilação Sul (IOS). 


\section{Resultados e Discussão}

Houve tendência, embora fraca, de redução da produtividade média, desde o início dos anos 1920 até a metade dos anos 1940 (Figura 3). Nesse período, houve forte queda de produtividade nos anos agrícolas 1942/ 1943 e 1944/1945, associada a precipitações pluviais inferiores à média climatológica, determinada por dois eventos de La Niña. A partir daí, até o final dos anos 1960, houve estagnação da produtividade da cultura, ou seja, mais de 20 anos com produtividade média no Estado quase constante e abaixo da média histórica. Grande parte desse período coincide com precipitações pluviais abaixo da média histórica (Figura 3). Nesse período, a produção de milho no Estado aumentou, pela expansão da área cultivada de 750 mil ha para 1,7 milhão de hectares.

O início da década de 70 marca uma reversão dessa situação e, a partir daí, o começo de um período com tendência para o incremento positivo da produtividade que perdura até 2003 (Figura 3). Segundo Mundstock (2004), esse período marca a entrada em cultivo do mi- lho híbrido duplo, de ciclo médio, melhor adaptado à lavoura mecanizada, a adoção de melhores práticas de manejo do solo, o maior uso de adubos, o uso de maiores densidades de semeadura e o início do plantio direto. Isto deu início à era de aumento de produção dessa cultura no Estado, principalmente pelo aumento de produtividade.

Os desvios de produtividade, negativos ou positivos, em torno da linha de tendência tecnológica, são causados pela ação do ambiente, especialmente as variáveis meteorológicas (Figura 3).

O período de maior variabilidade da produtividade coincide com maior variabilidade da precipitação pluvial, e a tendência mais acentuada de aumento da produtividade, na década de 90 e primeiros anos de 2000, coincide com a tendência de aumento da precipitação pluvial de outubro a março, causada pela ocorrência de pelo menos seis eventos de El Niño (Figura 3), que provocam anomalias positivas de precipitação pluvial, na primavera-início de verão, no Rio Grande do Sul, o que favorece as culturas dessa estação (Fontana \& Berlato, 1997; Berlato \& Fontana, 2003).

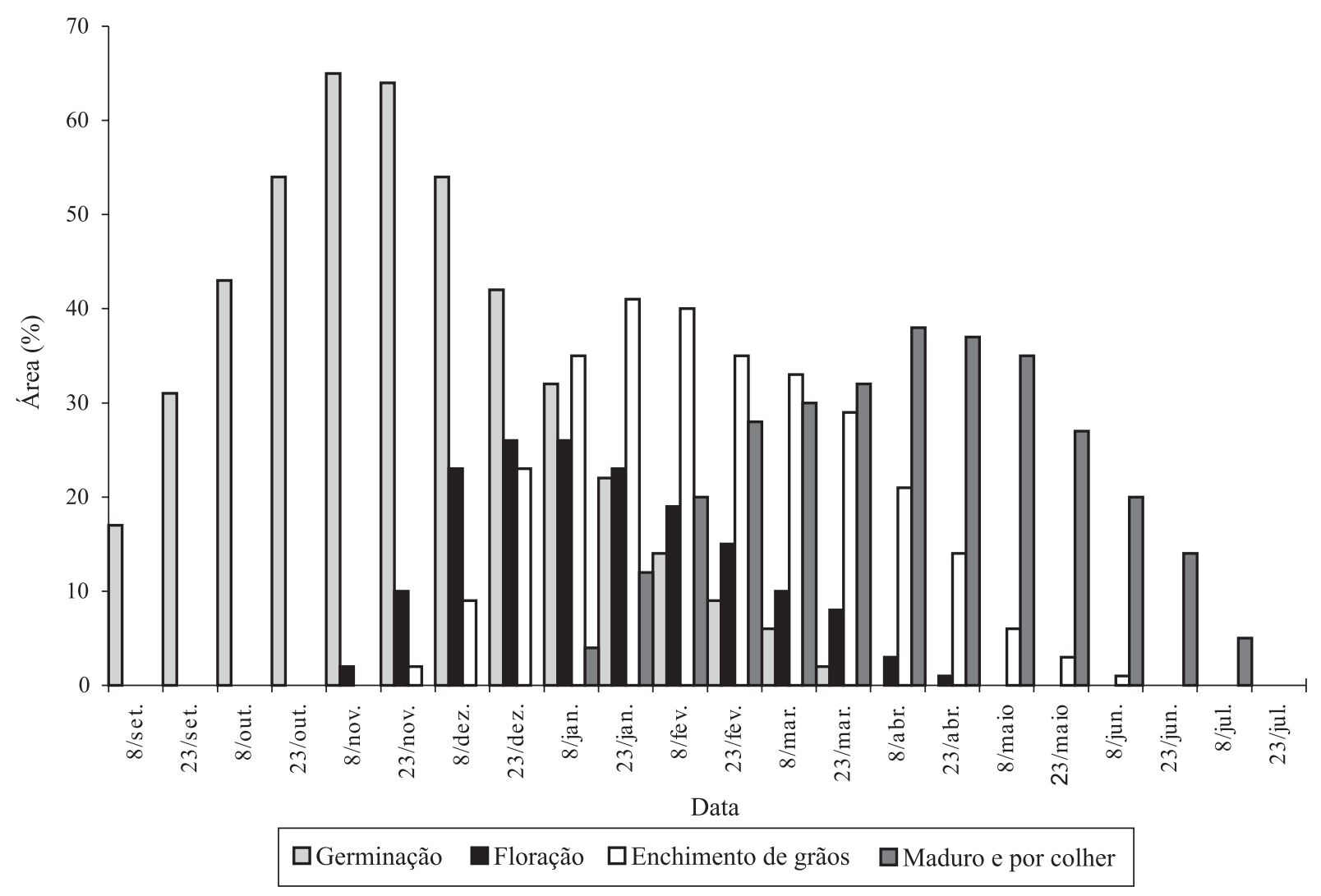

Figura 2. Calendário agrícola médio da cultura do milho, no Estado do Rio Grande do Sul. Fonte de dados: Emater-RS. 

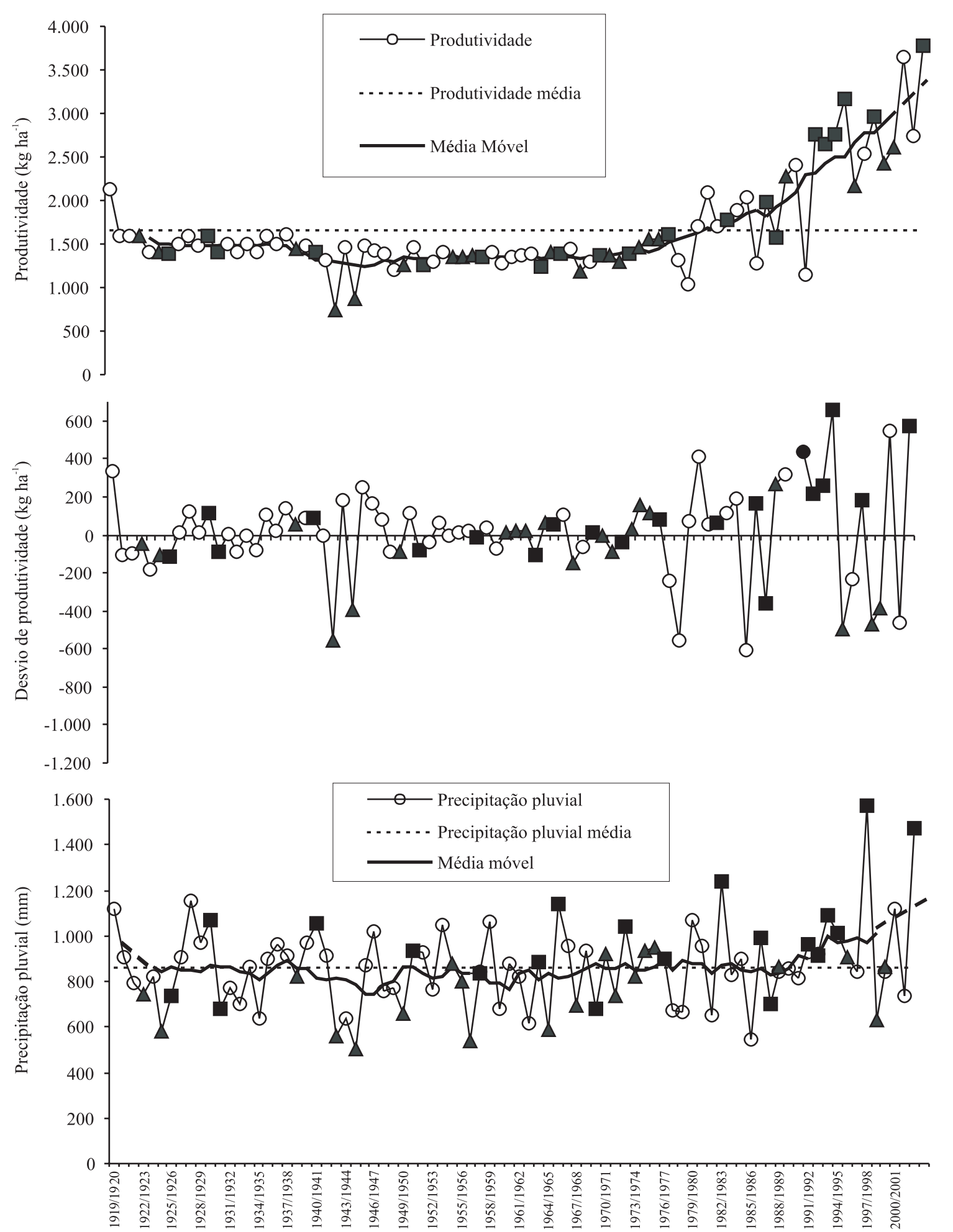

Ano agrícola

Anos de El Niño $\bigcirc$ Anos neutros $\quad \boldsymbol{\Delta}$ Anos de La Niña

Figura 3. Variação da produtividade do milho, no Estado do Rio Grande do Sul, variação dos desvios de produtividade e variação da precipitação pluvial, de outubro a março, período 1919/1920 a 2002/2003. 
O método de análise das relações clima-planta, com a retirada da tendência tecnológica da produtividade, pressupõe que a variável meteorológica a ser correlacionada seja estacionária, isto é, não apresente tendência. Portanto, possivelmente, parte do aumento da produtividade do milho, nos últimos anos, tenha ocorrido por causa da tendência de curto período de aumento da precipitação pluvial, determinado pela concentração de eventos El Niño nos últimos anos, conforme já foi demonstrado, em relação à soja, no Estado (Berlato \& Fontana, 1999).

A hipótese assumida na classificação dos tercis é de que não havendo associação entre produtividade do milho e ENOS, o número de anos, em cada tercil de produtividade, para uma dada fase do fenômeno, seria semelhante, aproximadamente, a um terço do total de observações para cada fase do ENOS (Tabela 1). Ao contrário, se a distribuição de freqüência observada for diferente disso, é possível que a produtividade esteja associada ao ENOS.

Há $45 \%$ de chance de obtenção de alta produtividade de milho (tercil superior), no Estado, em anos de El Niño, e 25\% de risco de baixa produtividade (tercil inferior) (Tabela 1). Em anos de La Niña há $45 \%$ de probabilidade de baixa produtividade (tercil inferior), e somente $15 \%$ de chance de haver produtividade alta (tercil superior) da referida cultura. Em anos neutros, sem ocorrência de ENOS, a distribuição de freqüência é de aproximadamente um terço em cada tercil de produtividade.

Nos anos de La Niña há maior freqüência de produtividade baixa (desvios negativos) em relação aos anos neutros (Figura 4); há risco relativamente alto $(>25 \%)$ de desvios negativos de produtividade igual ou maior que $300 \mathrm{~kg} \mathrm{ha}^{-1}$. Considerando-se a área colhida no Estado, no ano agrícola de 2000/2001, de aproximadamen-

Tabela 1. Tabela de contingência dos desvios de produtividade de milho, no Rio Grande do Sul, período 1919/1920 a 2002/2003, em tercis para fases de El Niño, La Niña e neutro ${ }^{(1)}$.

\begin{tabular}{lrrrr}
\hline Fases do & \multicolumn{3}{c}{ Tercis de produtividade } & Total \\
\cline { 2 - 4 } ENOS & Inferior & \multicolumn{1}{c}{ Médio } & \multicolumn{1}{c}{ Superior } & \\
\hline El Niño & $5(25 \%)$ & $6(30 \%)$ & $9(45 \%)$ & 20 \\
Neutro & $14(32 \%)$ & $14(32 \%)$ & $16(36 \%)$ & 44 \\
La Niña & $9(45 \%)$ & $8(40 \%)$ & $3(15 \%)$ & 20 \\
\hline Total & 28 & 28 & 28 & 84 \\
\hline
\end{tabular}

(1)Os números entre parênteses são a porcentagem do número de casos ocorridos. te 1,7 milhão de hectares, um desvio negativo de $300 \mathrm{~kg} \mathrm{ha}^{-1}$ corresponde a uma quebra de safra da ordem de meio milhão de toneladas de grãos de milho.

Na soja, os ganhos em produtividade com o El Niño são maiores do que as perdas de produtividade em eventos de La Niña (Berlato \& Fontana, 1999, 2003). La Niña é mais desfavorável ao milho por diferença de calendário agrícola. O milho é semeado a partir do início de agosto e, nessa época, parte do período reprodutivo (mais crítico em relação à falta d'água) coincide com estiagens provocadas normalmente por La Niña na primavera e início do verão. A soja é semeada mais tarde, e as estiagens de La Niña coincidem com o período vegetativo dessa cultura, mais tolerante à deficiência pluviométrica.

Em anos de El Niño, por outro lado, há pequena probabilidade de produtividade baixa e maior chance de produtividade alta (Figura 4).

Nos anos de El Niño há aproximadamente $75 \%$ de probabilidade de a precipitação pluvial ser maior que a mediana dos anos neutros, e mais de $80 \%$ de ser maior que a mediana dos anos de La Niña (Figura 5). Ao contrário, nos anos de La Niña há uma probabilidade de $75 \%$ da precipitação pluvial ficar abaixo da mediana dos anos neutros. Essa é a causa das diferenças de produtividade do milho, entre as fases de ENOS, pois sabe-se

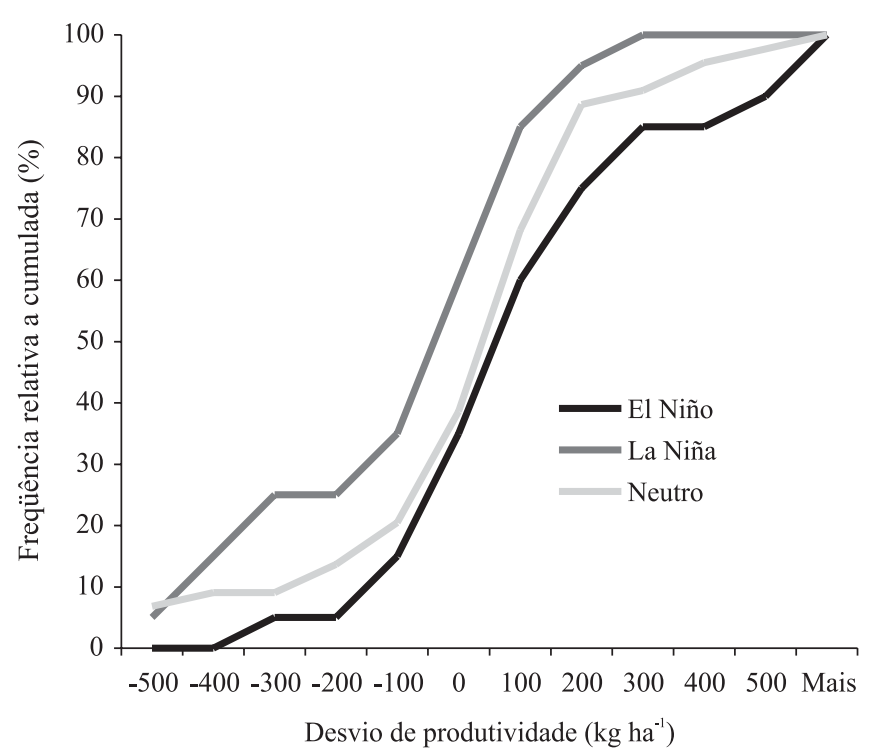

Figura 4. Freqüência acumulada (\%) dos desvios de produtividade do milho, em função das fases de ENOS no Rio Grande do Sul, período 1919/1920 a 2002/2003. 
que mesmo na metade norte do Estado, mais chuvosa, as precipitações pluviais normais são insuficientes para atender as necessidades hídricas da cultura do milho para alta produtividade. Isso também é comprovado pelos experimentos de irrigação, onde a suplementação de água, especialmente no período crítico da cultura, pode triplicar a produtividade média do Estado (Bergonci et al., 2001).

Podestá et al. (1999) encontraram impactos das fases do ENOS, na produtividade do milho na região pampeana argentina (nordeste da Argentina), um pouco maiores do que os mostrados no presente trabalho, es-

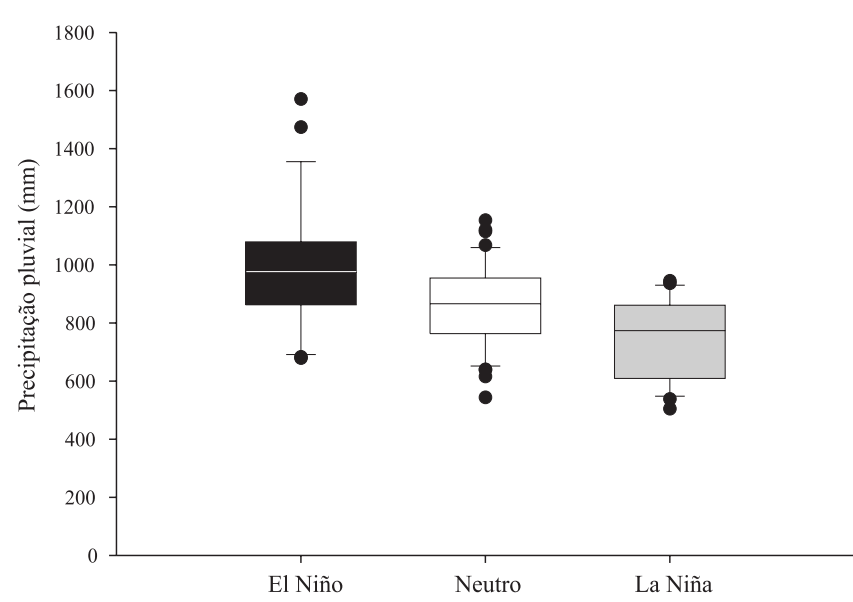

Figura 5. Distribuição da precipitação pluvial de outubro a março (diagrama de caixa), nos eventos El Niño, La Niña e neutro, da região significativa de produção de milho do Rio Grande do Sul, período 1919 a 2003. A linha horizontal no interior das caixas representa o percentil 50 (mediana); o final das caixas, os percentis 25 e 75; as barras, os percentis 10 e 90; os círculos cheios, os valores extremos. pecialmente em relação ao La Niña. A região pampeana da Argentina tem menor precipitação pluvial do que o Rio Grande do Sul, e possivelmente essa seja a causa de maiores impactos do ENOS, naquela região, com La Niña agravando o problema de deficiência hídrica e El Niño favorecendo maior disponibilidade hídrica para os cultivos agrícolas. No Rio Grande do Sul, mesmo em anos de La Niña, as precipitações pluviais médias climatologia de La Niña - do período de maior impacto do fenômeno (outubro-dezembro) variam, aproximadamente, de 60 a 115 mm (Fontana \& Berlato, 1997).

O ENOS causa impacto na produtividade do milho, porque interfere, principalmente, na precipitação pluvial, com a fase quente, El Niño, e ocasiona precipitação pluvial acima da média climatológica, e a fase fria, La Niña, ocasiona estiagem na primavera-início de verão, período no qual se desenvolve grande parte do calendário agrícola da cultura do milho, no Rio Grande do Sul (Figura 2).

O critério na partição da série em dois períodos (Tabela 2) foi o ponto de inflexão da linha de tendência tecnológica, a partir do qual passou a haver incrementos da produtividade e que corresponde, aproximadamente, ao ano agrícola 1970/1971 (Figura 3).

Os coeficientes de correlação foram todos significativos, com exceção do período nov./dez./jan. da série de dados de 1970/1971 a 2002/2003, em que a grande maioria é significativa a $1 \%$ de probabilidade (Tabela 2). Não houve, também, grande diferença dos valores do coeficiente de correlação nos três períodos analisados, o que pode significar que a dependência da produtividade do milho, em relação à precipitação pluvial, não mudou, apesar do melhoramento genético e das novas tecnologias de produção dessa cultura. Em dois dos três

Tabela 2. Coeficientes de correlação entre precipitação pluvial da região significativa de produção de milho (média de oito estações), em diferentes períodos, e produtividade média de milho, de todo o Estado do Rio Grande do Sul, série de dados de 1919/1920 a 2002/2003(1).

\begin{tabular}{lccc}
\hline Período & \multicolumn{3}{c}{ Períodos (anos) } \\
\cline { 2 - 4 } & $1919 / 1920-2002 / 2003$ & $1919 / 1920-1969 / 1970$ & $1970 / 1971-2002 / 2003$ \\
\hline Out./nov./dez. & $0,383^{* *}$ & $0,348^{* *}$ & $0,440^{*}$ \\
Nov./dez./jan. & $0,379^{* *}$ & $0,588^{* *}$ & $0,335^{\text {ns }}$ \\
Dez./jan./fev. & $0,453^{* *}$ & $0,519^{* *}$ & $0,468^{* *}$ \\
Jan./fev./mar. & $0,406^{* *}$ & $0,385^{* *}$ & $0,452^{*}$ \\
Nov./dez./jan./fev. & $0,446^{* *}$ & $0,594^{* *}$ & $0,397^{*}$ \\
Dez./jan./fev./mar. & $0,459^{* *}$ & $0,495^{* *}$ & $0,495^{* *}$ \\
Outubro a março & $0,517^{* *}$ & $0,517^{* *}$ & $0,553^{* *}$ \\
\hline Número de anos & 84 & 51 & 33 \\
\hline
\end{tabular}

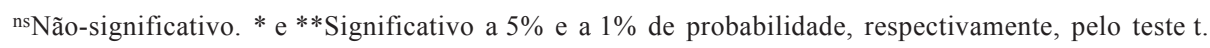


períodos analisados (toda a série, e para 1970/1971 a 2002/2003), a maior correlação foi do período do calendário agrícola integrado de outubro a março (Tabela 2). Esses meses compreendem desde a germinação até grande parte do período de enchimento de grãos (Figura 2). Os períodos de floração e enchimento de grãos do milho são os mais sensíveis à variação de precipitação pluvial (períodos críticos em relação à água).

A função de relação entre os desvios da precipitação pluvial (desvios da média de todo o período) e os desvios de produtividade foi ajustada sem o dado de 1990/1991 (Figura 6). Esse ano, apesar de provocar uma das maiores quebras na produtividade de milho do Estado, teve pequeno desvio negativo de precipitação pluvial de outubro a março, porque em outubro e primeira quinzena de novembro de 1990 houve chuvas intensas, mas todo o restante do período, até maio-junho de 1991, foi extremamente seco (Berlato \& Fontana, 2003). Em vista disso, foi considerado um dado excepcional (raro). Incluindo o dado do referido ano, o coeficiente de determinação da função decresceu de 0,513 para 0,406 .

Com base no $\mathrm{R}^{2}$, a variável precipitação pluvial explica mais de $50 \%$ da variação interanual da produtivi-

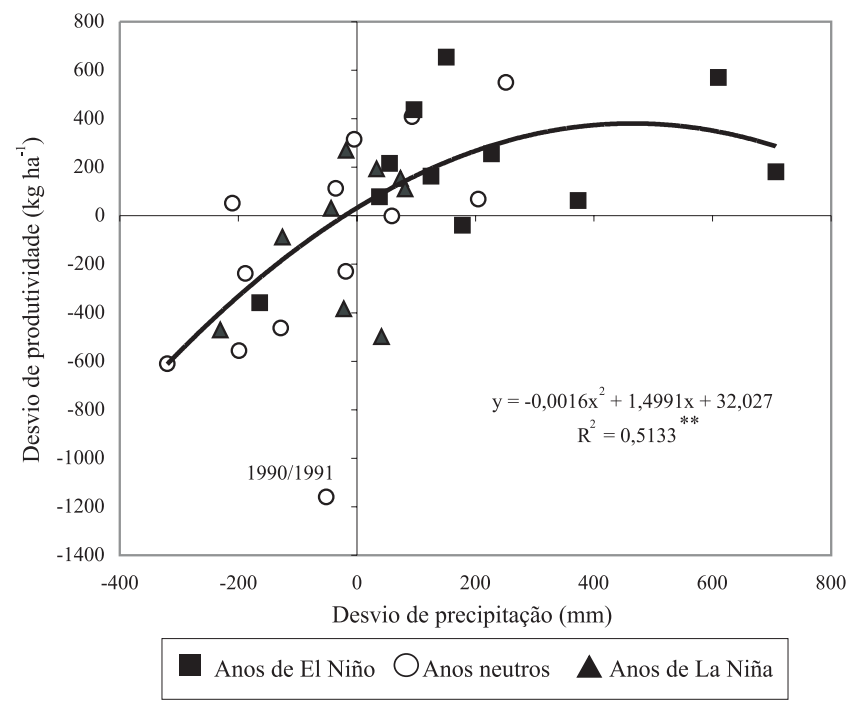

Figura 6. Relação entre os desvios de precipitação pluvial de outubro a março, da região significativa de produção do milho, no Rio Grande do Sul, e os desvios de produtividade do milho de todo o Estado, série de dados de 1970/1971 a 2002/ 2003. ${ }^{* *}$ Significativo a $1 \%$ de probabilidade pelo teste $\mathrm{F}$. dade do milho no Estado (Figura 6). A precipitação pluvial média, de oito estações meteorológicas da região significativa de produção do milho, explica a variação da produtividade média de todo o Estado. Isso já foi verificado para a soja (Berlato \& Fontana, 1999), em que a precipitação pluvial média de apenas seis estações, situadas no noroeste do Estado, explica cerca de $80 \%$ da variabilidade da produtividade média de todo o Estado. O ponto de máxima produtividade dessa função corresponde a um desvio de $469 \mathrm{~mm}$ de precipitação pluvial, o que representa, em média, para o período de outubro a março, cerca de $78 \mathrm{~mm}$ mês $^{-1}$ mais do que a normal climatológica.

Com relação à produtividade de lavoura em todo o Estado, onde, como já mencionado, diversas variáveis atuam na definição da produtividade final dessa cultura, uma variável que explique um pouco mais de $50 \%$ da variação da produtividade é, sem dúvida, a variável de maior peso, e a que deve ser inserida primeiro em modelos de previsão de produtividade, por exemplo, para efeitos de previsão de safra.

Os dois índices que apresentaram maior associação com a produtividade de milho, no Rio Grande do Sul, foram a anomalia de TSM de El Niño 3.4 e IOS (Figura 7).

Houve forte tendência de que a anomalia positiva de TSM e IOS negativo favoreçam a produtividade do milho, com maior concentração de pontos nos quadrantes I (Figura 7a) e II (Figura 7b); ou seja, nas anomalias positivas de TSM, em cerca de $67 \%$ dos casos, os desvios de produtividade foram positivos, e no IOS negativo, em cerca de $70 \%$ dos casos, os desvios de produtividade foram, também, positivos.

No caso de TSM de El Niño 3.4, dos 11 eventos de El Niño ocorridos no período, em nove (82\%) os desvios de produtividade foram positivos, e no caso de IOS, em dez (91\%) os desvios também foram positivos.

No Nordeste brasileiro, Rao et al. (1997) encontraram correlações significativas entre IOS e produtividade do milho, só que, naquela região, o sinal é trocado: o La Niña produz maiores precipitações pluviais (IOS positivo).

No caso de anomalias negativas de TSM e IOS positivos parece não haver uma tendência definida. Notase, porém, que os desvios negativos de produtividade provocados por La Niña são muito maiores do que os desvios positivos (Figura 7). 

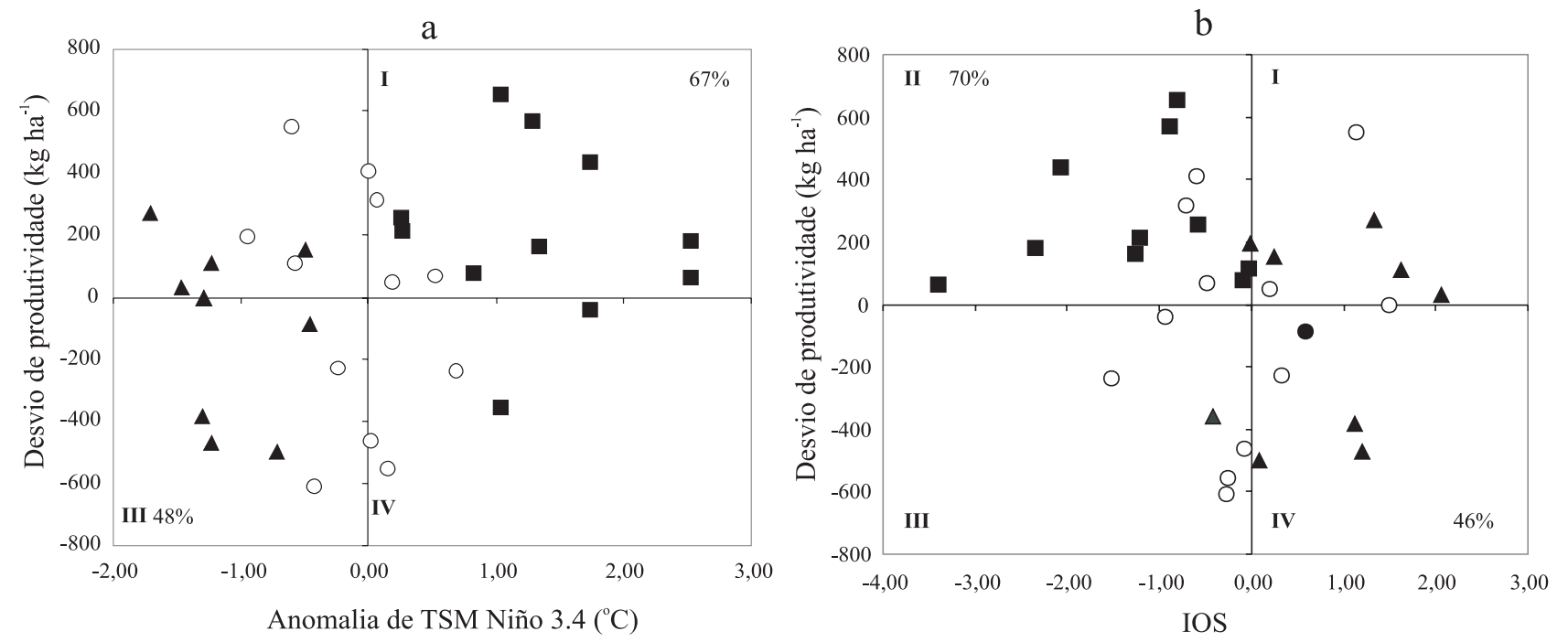

Anos de El Niño O Anos neutros $\boldsymbol{\Delta}$ Anos de La Niña

Figura 7. Relação entre os desvios de produtividade de milho no Estado do Rio Grande do Sul e a anomalia da Temperatura da Superfície do Mar (TSM) do El Niño 3.4 (a), e o Indice de Oscilação Sul (IOS) (b), média do período do calendário agrícola de outubro a março, período 1969/1970 a 2002/2003.

\section{Conclusões}

1. O El Niño determina ganhos e La Niña determina queda na produtividade do milho no Rio Grande do Sul.

2. A precipitação pluvial mais importante do calendário agrícola do milho, no Estado, é a que vai de outubro a março, seguida da que vai de dezembro a março.

3. Águas quentes no Oceano Pacífico equatorial central e Oscilação Sul negativa determinam, em geral, ganhos em produtividade do milho, no Estado.

4. As informações obtidas são úteis para se decidir quanto a alternativas de manejo da cultura do milho, como: época de semeadura e uso de insumos modernos, com a finalidade de diminuir prejuízos ou favorecer ganhos em produtividade, frente a uma previsão de El Niño ou La Niña.

\section{Agradecimentos}

Ao $\mathrm{CNPq} / \mathrm{PSPPG}$ e Fapergs, pelo financiamento parcial do trabalho; ao CNPq, pelas bolsas concedidas a Moacir Antonio Berlato e Denise Cybis Fontana.

\section{Referências}

BERGONCI, J.; BERGAMASCHI, H.; SANTOS, O.A.; FRANÇA, S.; RADIN, B. Eficiência da irrigação em rendimento de grãos e matéria seca de milho. Pesquisa Agropecuária Brasileira, v.36, p.949-956, 2001.
BERLATO, M.A.; FONTANA, D.C. El Niño e La Niña: impactos no clima, na vegetação e na agricultura do Rio Grande do Sul; aplicações de previsões climáticas na agricultura. Porto Alegre: Ed. da UFRGS, 2003. 110p.

BERLATO, M.A.; FONTANA, D.C. Variabilidade interanual da precipitação pluvial e rendimento da soja no Estado do Rio Grande do Sul. Revista Brasileira de Agrometeorologia, v.7, p.119-125, 1999.

CARMONA, L.C.; BERLATO, M.A. El Niño e La Niña e o rendimento de arroz irrigado no Estado do Rio Grande do Sul. Revista Brasileira de Agrometeorologia, v.10, p.147-152, 2002.

CUNHA, G.R.; DALMAGO, G.A.; ESTEFANEL, V. ENSO influences on wheat crop in Brazil. Revista Brasileira de Agrometeorologia, v.7, p.127-138, 1999.

DIAZ, A.F.; STUDZINSKI, C.D.; MECHOSO, R.C. Relationship between precipitation anomalies in Uruguay and shouthern Brazil and sea surface temperature in the Pacific and Atlantic Oceans. Journal of Climate, v.11, p.251-271, 1998.

FONTANA, D.C.; BERLATO, M.A. Influência do El Niño Oscilação Sul (ENOS) sobre a precipitação do Estado do Rio Grande do Sul. Revista Brasileira de Agrometeorologia, v.5, p.127-132, 1997.

FONTANA, D.C.; BERLATO, M.A. Relação entre El Niño Oscilação Sul (ENOS), precipitação e rendimento do milho no Estado do Rio Grande do Sul. Pesquisa Agropecuária Gaúcha, v.2, p.3946, 1996.

GRIMM, A.; FERRAZ, S.E.T.; GOMES, J. Precipitation anomalies in southern Brazil associated with El Niño and La Niña events. Journal of Climate, v.11, p.2863-2880, 1998. 
MATZENAUER, R. Modelos agrometeorológicos para estimativa da produtividade de milho em função da disponibilidade hídrica no Estado do Rio Grande do Sul. 1994. 172p. Tese (Doutorado) - Universidade Federal do Rio Grande do Sul, Porto Alegre.

MATZENAUER, R.; BERGAMASCHI, H.; BERLATO, M.A.; RIBOLDI, J. Relações entre rendimento de milho e variáveis hídricas. Revista Brasileira de Agrometeorologia, v.3, p.85-92, 1995.

MATZENAUER, R.; FONTANA, D.C. Relação entre rendimento de grãos e altura de chuva em diferentes períodos de desenvolvimento do milho. In: CONGRESSO BRASILEIRO DE AGrometeorologia, 5., 1987, Belém. Coletânea de trabalhos. Belém: SBA, 1987. p.3-6.

MONTECINOS, A.; DIAZ, A.; ACEITUNO, P. Seasonal diagnostic and predictability of rainfall in subtropical South America based on tropical Pacific SST. Journal of Climate, v.13, p.746-758, 2000.

MUNDSTOCK, C.M. A evolução da genética e da tecnologia de cultivo de milho no Rio Grande do Sul. Porto Alegre: Departamento de Plantas de Lavoura, Universidade Federal do Rio Grande do Sul; Evangraf, 2004. 34p.

OLIVEIRA, G.S. de. O EI Niño e você: o fenômeno climático. São José dos Campos: Transtec, 1999. 116p.

PODESTÁ, G.; LETSON, D.; MESSINA, C.; ROYCE, F.; FERREYRA, R.A.; JONES, J.; HANSEN, J.; LLOVET, I.; GRONDONA, M.; O`BRIEN, J.J. Use of ENSO-related climate information in agricultural decision making in Argentina: a pilot experience. Agricultural Systems, v.74, p.371-392, 2002.

PODESTÁ, G.P.; MESSINA, C.D.; GRONDONA, M.; MAGRIN, G.O. Association between grain crop yields in central-eastern Ar- gentina and E1 Niño-south oscillation. Journal of Applied Meteorology, v.38, p.1488-1498, 1999.

PUCHALSKI, L.A. Efeitos associados ao El Niño e La Niña na temperatura média, precipitação pluvial e no déficit hídrico no Estado do Rio Grande do Sul. 2000. 83p. Dissertação (Mestrado) - Universidade Federal do Rio Grande do Sul, Porto Alegre.

RAO, V.B.; HADA, K. Characteristics of rainfall over Brazil: annual variations and connections with southern oscillation. Theoretical and Applied Climatology, v.212, p.81-91, 1990.

RAO, V.B.; SÁ, L.D.A.; FRANCHITO, S.H.; HADA, K. Interannual variations of rainfall and corn yields in Northeast Brazil. Agricultural and Forest Meteorology, v.85, p.63-74, 1997.

RIBEIRO, A.S. Fisionomia da agropecuária: culturas. Porto Alegre: Emater/RS; Ascar, 2003. 43p. (Caderno, 2). Disponível em: http:// www.emater.tche.br. Acesso em: abr. 2004.

ROPELEWSKI, C.F.; HALPERT, M.S. Global and regional scale precipitation patterns associated with the E1 Niño/southern oscillation. Monthly Weather Review, v.115, p.1606-1626, 1987.

STUDZINSKI, C.D.; DIAZ, A.F. Relação da precipitação no sul do Brasil-Uruguai com a temperatura da superfície do mar (TSM) por correlações canônicas (CCA). In: PESSOA, M.L.; MINE, M.R.M.; LEITE, E.A. (Coord.). Meteorologia e hidrologia: aspectos e considerações no contexto brasileiro. Curitiba: Sistema Meteorológico do Paraná (Simepar), 1994. p.191-205.

TRENBERTH, K.E. The definition of El Niño. Bulletin of the American Meteorological Society, v.78, p.2771-2777, 1997.

WILKS, D.S. Statistical methods in the atmospheric sciences: an introduction. New York: Academic Press, 1995. 467p.

Recebido em 26 de julho de 2004 e aprovado em 6 de dezembro de 2004 